\title{
PRE-OPERATIVE SPINE EMBOLISATION FOR SPINAL TUMORS AND METASTASES: 6 YEARS EXPERIENCE AT PUSAT PERUBATAN UNIVERSITI KEBANGSAAN MALAYSIA
}

\author{
Mohd Naim Mohd Yaakob ${ }^{1 *}$, Nik Azuan Nik Ismail2 ${ }^{2}$, Ahmad Sobri Muda1 \\ ${ }^{1}$ Radiology Department, Hospital Pengajar Universiti Putra Malaysia \\ ${ }^{2}$ Radiology Department, Pusat Perubatan Universiti Kebangsaan Malaysia
}

\section{Corresponding author :}

*Dr. Mohd Naim Mohd Yaakob, Radiology Department, Hospital Pengajar Universiti Putra Malaysia (HPUPM), 43400

Serdang, Selangor, Malaysia. Tel: +60397695001. Email: mnaim.yaakob@upm.edu.my.

DOI: https://doi.org/10.32896/cvns.v2n1.5-12

Published: 07.08.2020

\begin{abstract}
Objective: Our aim is to determine the average intraoperative blood loss in patients who underwent pre-operative spinal tumour embolisation in PPUKM from 2010 until 2016 and to compare with other centres from literature review.

Material And Methodology: 15 patients in PPUKM with spinal tumour and spinal metastatic disease underwent pre-operative embolisation before palliative spinal surgery between 2010 and 2016 in PPUKM. Intraoperative blood loss during palliative spinal surgery was documented obtaining the average and median blood loss. Secondary analyses were made on the amount of intraoperative blood loss in comparison to the embolisation materials, degree of embolisation completion, primary malignancy, level of spinal metastatic involvement and total operating time.

Result: The average and median intraoperative blood loss during palliative spinal surgery were $1480 \mathrm{mls}$ and $1000 \mathrm{mls}$ respectively, which is comparable with other centre from literature review. Significant difference is noted in intraoperative blood loss between the different embolisation materials used $(\mathrm{P}<0.01) .10$ patients had complete embolisation and 4 patients had incomplete embolisation with significant difference in terms of blood loss between these 2 groups with $\mathrm{P}$ value of $<0.01$. There was significant positive correlation between operating time and intra-operative blood loss, whereby the longer the operation, the higher the amount of blood loss.

Conclusion: The average intraoperative blood loss in patients with pre-operative spinal tumour embolisation in PPUKM is comparable to other centres from literature review thus pre-operative tumour embolisation can reduce perioperative haemorrhage. However, larger study is needed to further analyse correlation between these factors in affecting intraoperative blood loss.
\end{abstract}

Keywords: Pre-embolisation, intraoperative blood loss, spinal tumour, palliative spinal surgery

\section{INTRODUCTION}

Spinal tumour consists of primary and secondary (metastasis). Primary bone tumour accounts about $0.5 \%$ of all newly diagnosed tumour, and 5\% out of these tumours arises from the spine. Nonetheless, the most common spinal tumour is metastasis as two-third of cancer patients will develop bone metastasis ${ }^{1}$. Bone is the most common site for metastasis followed by lung and liver ${ }^{2}$ with spine being the most common site for bone metastasis ${ }^{3}$. Body of vertebra is the first to be involved, but destruction of pedicle is the most common finding in plain film. Thoracic and lumbar spines are the common area to be involved ${ }^{4,5,6}$. D. Togawa and K. U. Lewandrowsky (2006) suggested that the cervical spine is the least to be involved.

They also found out that more than $50 \%$ involved multilevel, $10 \%$ to $38 \%$ have multiple, non-contiguous segments involved ${ }^{7}$. Spinal metastasis may cause pain, instability, and neurological injuries with loss of control of urinary and rectal sphincters. Symptomatic spinal cord involvement occurs in about 18000 cases per year. ${ }^{8}$
In terms of prognosis, once the cancer has spread, rarely it can be cured. Even if cure is no longer possible, palliative treatment of the spinal cancer may be able to help patient to live longer and improve quality of life. Among the main treatment goals of surgical intervention in spinal metastasis are; to provide spinal stability, to relieve symptomatic pain and to obtain histological specimen for diagnosis. 9,10,11 Currently, some orthopaedic surgeons even advocate vertebral body resection and stabilisation as preventive measure for imminent spinal instability and/or supplementation for radiation therapy. ${ }^{12}$

Previous palliative surgery for spinal tumours was laminectomy however the result of solely laminectomy alone was unfavourable $\mathrm{e}^{13,14}$. Thus, most cases are currently treated by direct decompression and stabilisation with instrumentation. These changes in approach have improved the surgical outcome. Unfortunately, the main documented drawback of these procedures is excessive and sometime lifethreatening bleeding. ${ }^{15,16}$ 
Spinal tumour embolisation has been proven to be a safe procedure and able to reduce intraoperative blood loss and reduce operating time ${ }^{17}$. However, there are several studies showing no significant difference between preoperative embolisation with non-pre-embolisation cases. Berkefeld J, et al 1999 suggested that pre-operative embolisation does improve surgical outcome but this depends on the type of primary tumour16. Clausen C et al 2015 suggested that preoperative embolisation of spinal metastasis, independent of primary tumour, does not reduce intraoperative blood loss or blood transfusion, but able to reduce the operative time. Small reduction in blood loss has been demonstrated in the management of hypervascular spinal metastasis ${ }^{18}$. This study is intended to see the effect of pre-operative embolisation in spinal metastatic surgery, particularly in the local setting, as our institution has started this service since 2010 .

\section{MATERIAL AND METHODS}

Subject and Procedures: This retrospective study was performed in the department of radiology, Pusat Perubatan Universiti Kebangsaan Malaysia (PPUKM). Data was retrieved from RIS (Hospital Radiology information system) as well as from patient database file from department of record. Data were taken from January 2010 until December 2016.

Cases for pre-operative spinal embolisation tumour were filtered from the database of interventional unit of PPUKM from the mentioned dates. Inclusion criteria's were mainly to include all patients who have gone through preoperative spinal embolization that was done within the selected time frame. From the list obtained, cases were reviewed further through the post-operative notes to determine the tumour type and intra-operative data. Multiple parameters were taken into accounts including the demographic data, type of spinal tumour / site of primary tumour for spinal metastasis, materials used during embolisation, completion of the embolisation, type of spinal surgery, intra-operative blood loss, duration of the operation and intra- or post-operative blood transfusion. Complete embolisation is defined by achieving more than $90 \%$ tumour devascularization post embolisation. This is judged based on images post embolisation as well as post embolisation report.

Statistical analysis were done using multiple statistical test as well as Statistical Package for Social Sciences (SPSS) software to see the average intraoperative blood loss in the spinal surgery, in those who have went through pre-operative spinal embolisation. Comparison were made with the average blood loss seen in the literature review cases. The other secondary objectives for this study include the difference of average blood loss based on the tumour types, materials used during embolisation, operative time and completion of embolisation.

\section{RESULTS}

A total of 24 patients were eligible for this study based on the inclusion criteria, however, 9 patients were excluded due to unavailability of written records in the database. From these 15 subjects, 9 were male and 6 were female. Age of subjects were ranged from 22 until 70 years old. Median and mean age were 54 and 52 years old respectively. 10 of our subjects were Malay and 5 were Chinese. Intraoperative blood loss in our patient ranged from $300-5000 \mathrm{ml}$.

Average blood loss was $1480 \mathrm{ml}$ whilst median blood loss was $1000 \mathrm{ml}$. From Figure 1, the highest intraoperative blood loss $(5000 \mathrm{ml})$ was recorded in patient with multiple myeloma which had metastasized to T12, L1 and L5 vertebrae. Other primary tumours with spinal metastasis that had large amount blood loss in our study include renal cell carcinoma $(4000 \mathrm{ml})$ and hemangiopericytoma $(2200 \mathrm{ml})$. Primary spinal bony tumour was only multiple myeloma which occurred at T12/L1 and L4 levels. The rest of the spinal tumours were metastatic disease.

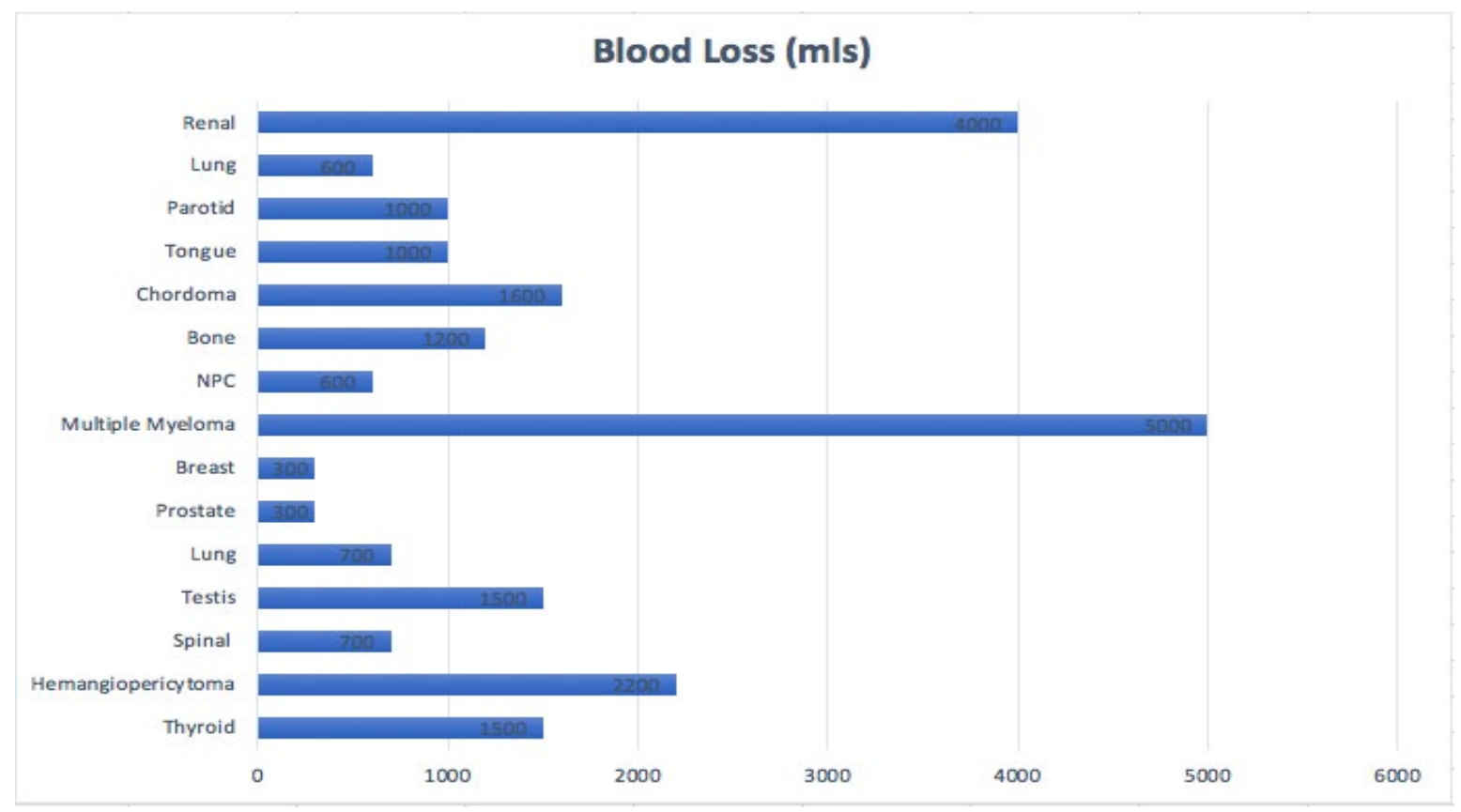

Figure 1 
In our perioperative embolisation, multiple types of embolic materials were used in order to devascularized the spinal metastases prior to the surgery. Gelfoam, polyvinyl alcohol (PVA) particles and coils were the materials that were frequently used for embolisation. In some of the cases, these materials were combined in order to achieve better or complete devascularisation. Out of 15 patients, 5 patients were embolised using PVA, 4 patient embolised using combined embolic agents, 3 patients had coils, 2 patients had Gelfoam and remaining 1 patient had temporary embolization via balloon-assisted vertebrectomy for $\mathrm{C} 2$ chordoma. One way ANOVA test showed there was significant difference in blood loss between patients that used different embolic materials. Table 2 summarised the usage of embolic materials and their relation with the intraoperative blood loss

\begin{tabular}{|c|c|c|}
\hline Embolic Agent & Cases & Average Blood Loss (in ml) \\
\hline PVA & 5 & 1660 \\
\hline Combined & 4 & 1950 \\
\hline Gel foam & 2 & 1250 \\
\hline Coils & 3 & 666 \\
\hline Stent & 1 & 1600 \\
\hline \multicolumn{2}{|c|}{ P Value } & 0.00019 \\
\hline
\end{tabular}

Table 2

The degree of tumour devascularisation has significant role in intraoperative blood loss. From our study, there was 10 patients had complete embolisation with another patient had on- table balloon-assisted vertebrectomy. The remaining 4 patients did not achieve complete embolisation. T-test showed there was significant difference in intraoperative blood loss between those who had complete embolisation and those with incomplete embolisation with $\mathrm{P}$ value of less than 0.01 (Table 3).

\begin{tabular}{|c|c|c|}
\hline $\begin{array}{l}\text { Degree of Embolisation (Complete / } \\
\text { Incomplete) }\end{array}$ & Number of Cases & Mean Blood Loss (in ml) \\
\hline Complete & 10 & 1360 \\
\hline Incompete & 4 & 1900 \\
\hline \multicolumn{2}{|c|}{$\mathrm{P}$ value } & 0.0017 \\
\hline
\end{tabular}

Table 3

We also studied the relation between operating time and the amount of intraoperative blood loss. Operating time ranged from $68 \mathrm{~min}$ (1.1 hour) to $620 \mathrm{~min}$ (10.3 hours). Average operating time was 214 min (3.6 hours) and median operating time was $185 \min$ (3.1 hours). Pearson correlation test showed positive correlation between the amount of blood loss and the operating time with Pearson value of 0.78 (Figure 2).

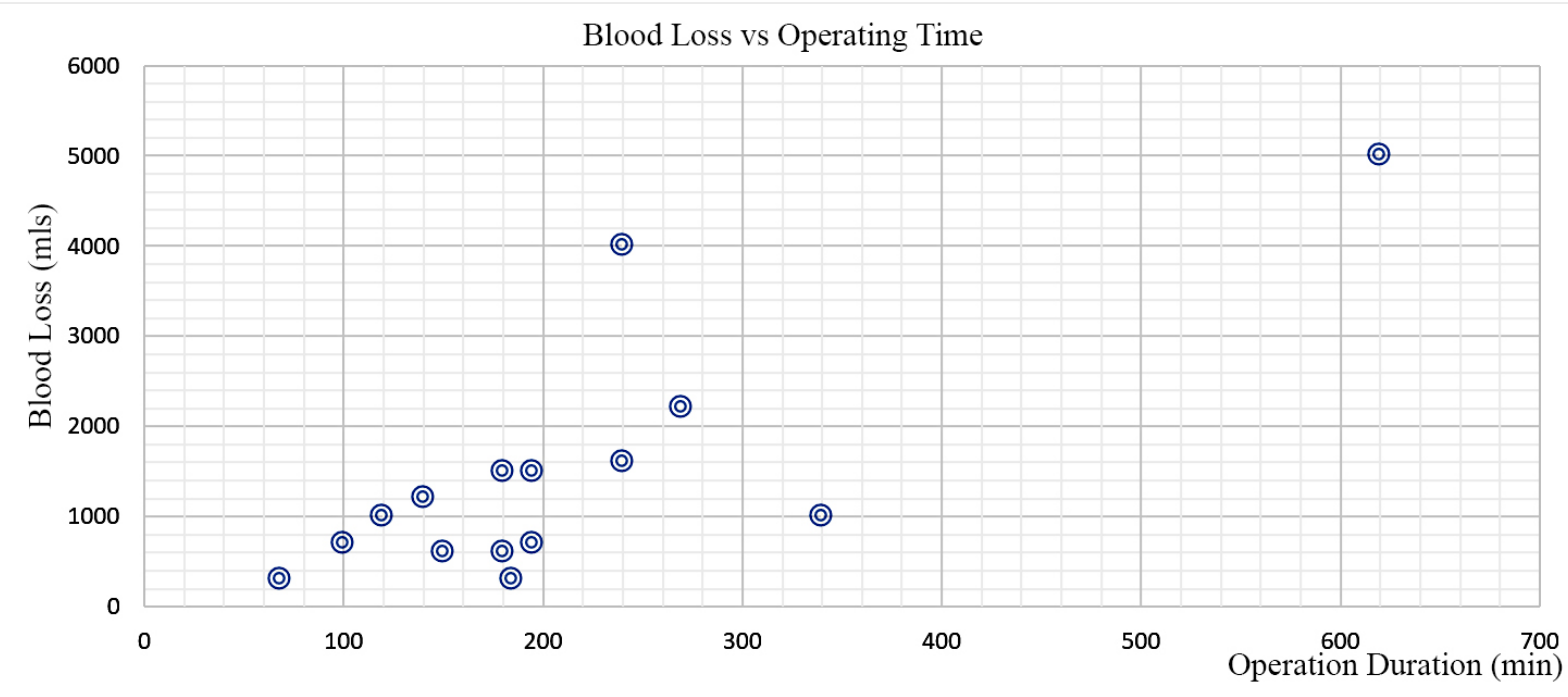

Pearson correlation: 0.78

Figure 2 


\section{DISCUSSION}

As mentioned before, average and median blood loss were $1480 \mathrm{ml}$ and $1000 \mathrm{ml}$ respectively. In 2016, Griessinauer J et al published a systemic review and meta-analysis on multiple studies on pre-operative embolisation done from 1990 to $2008^{19}$. In this study, it was documented that mean and median intraoperative blood loss ranged from $1100 \mathrm{ml}$ to $4450 \mathrm{ml}$. Based on this, our mean blood loss fell within this range.

As of to date, only one case controlled study did a comparison between the amount of blood loss in pre- operative embolised group and non-embolised group. It was published by Roshan Jha et al in 2016 comparing 26 patients who underwent pre-operative embolisation with 28 patients in the control group (without pre-embolisation). The mean estimated blood loss (EBL) for the pre-embolised group was $1300 \mathrm{ml}$ and the non-embolised group was $1800 \mathrm{ml}^{20}$. Table 4 showed comparison of estimated and mean blood loss from our study in comparison with other studies from literature reviews

\begin{tabular}{|l|l|l|l|l|}
\hline Ref. & Year & No. of Patients & Type of Study & Result (ml) \\
\hline Thiex et al & 2013 & 104 & Retrospective & EBL: $100-15000$ \\
\hline Ibrahim et al & 2013 & 18 & Retrospective & $\begin{array}{l}\text { EBL: } 1100-2600 \\
\text { MBL: } 1400\end{array}$ \\
\hline Kobayashi et al & 2012 & 62 & Retrospective & $\begin{array}{l}\text { EBL: } 250-11000 \\
\text { MBL: } 2554\end{array}$ \\
\hline Al-Hadithy et al & 2011 & 26 & Retrospective & EBL: $100-1800$ \\
\hline Zhang et al & 2009 & 47 & Retrospective & EBL: $705 \pm 120$ \\
\hline Lee et al & 2008 & 6 & Prospective & EBL: $200-830$ \\
\hline Jha R et al & $2012-13$ & 26 (study group) & Case control & EBL: $250-2900$ \\
\hline Our study & $2010-2016$ & 15 & Retrospective & EBL: $800-6000$ \\
\hline & & & & $\begin{array}{l}\text { EBL: } 300-5000 \\
\text { MBL: } 1480 \\
\text { Median: } 1000\end{array}$ \\
\hline
\end{tabular}

EBL: Estimated blood loss

MBL: Mean blood loss

From the result, we also noted that the highest intraoperative blood loss was in patient who had spinal metastasis from multiple myeloma, followed by renal cell carcinoma and hemangiopericytoma due to their hypervascular nature. This is consistent with literature reviews supporting this finding. Sreejit Nair et al published a study on pre-operative embolisation of hypervascular spinal tumour in 2013. They divided the spinal column tumour according to the tumoral blushed demonstrated in angiogram into 0 until 3, with 3 being the worst which demonstrated severely increased tumoral blush with early arteriovenous shunting ${ }^{21}$. Multiple myeloma, hemangiopericytoma and renal cell carcinoma were categorised under high tumoral vascularity.

Overall, PVA particulate embolic agents were the most frequently used in our patients (5 patients). Theoretically, particle agents would end up and accumulate in the tumour capillary bed thus producing sufficient tumour devascularisation ${ }^{22}$. Pertaining to our study, there were variable size of particles used, mainly from 250 - 350 micron until 355 - 500 micron, depending on the vessel size, type of vessels as well as preference of the operating interventional radiologists based on their experience. According to Berkefeld J in 1999, medium sized particles (150 micron 250 micron) are considered favourable for occlusion of the capillary bed, because tumour capillaries are theoretically around $200 \mu \mathrm{m}$ in diameter ${ }^{16}$. If obvious anastomosis with normal spinal cord vasculature was present, larger particles
$(>250 \mu \mathrm{m})$ are preferred, mainly to avoid spinal cord ischemia. Due to limited sample size, we were unable to assess superiority of different particles size over another in this current study.

Combined embolic agent materials were used in 4 patients. Combined materials help in some cases to achieve greater devascularisation. Most common combination in our study was PVA and coils (3 out of 4 cases), whilst combination of gelfoam and coils were only used once. Additional usage of coils with PVA was recommended to occlude ventral branch of feeding artery, hence achieving better tumour devascularisation ${ }^{21}$. However, one must aware that ventral branch occlusion may give rise to complication such as skin necrosis. None of our patients developed such complication which may be explained by presence of rich collateral network which are essential to prevent such occurrence.

Coils were used in 3 of our patients. According to Barkefeld in 1999, coils were preferred embolic material especially by the orthopaedic surgeon as it was believed to cause lesser neurologic impairment than Gelfoam powder. However, recent studies showed that using only coils will give inadequate devascularisation ${ }^{16}$. In our study, coils were used when the feeding artery was large enough to accommodate coils and was deployed to achieve better embolisation completion. In addition, personal preference by the operating interventional radiologist also played important 
role in choosing the embolic material. Coils were also used in order to prevent non-targeted embolisation especially in the presence of co-supply or communication with other vital structures. Although from our study, statistical data using ANOVA test showed significant difference in intraoperative blood loss in patients with different embolic materials, we were unable to determine the superiority of one embolic agent over another. A further in depth study with larger sample size is essential in order to achieve this.

Gelfoam slurry was only used in two patients. It, theoretically gives better tumour penetration if injected slowly over longer period due to its liquified nature. This theory are supported by reports of superior penetration during the treatment of vascular malformation ${ }^{23,24}$. However, the possibility of non-targeted embolisation is known to be high with Gelfoam. Santillan in 2011 mentioned that liquid embolic materials have the ability to achieve greater penetration of tumour vasculature however, it was more difficult to control and may result in advertent embolisation 25 .

As mentioned earlier, only two patients in our study were solely embolised using Gelfoam. In the first case, the patient was diagnosed with left orbital hemangiopericytoma with C5 spinal metastasis. He was embolised with Gelfoam because selective cannulation of the feeding arteries were difficult. In fact, we were unable to embolise one of the feeding artery arising from the left vertebral artery.

The second case of solely Gelfoam usage was in a patient with prostate cancer metastasis to multilevel vertebral bodies. In this particular case, there was no significant tumoral blushed seen from feeding artery at T12 level (vertebra that aimed for vertebrectomy). We decided to inject gel foam for temporary embolisation of the small capillary supply. There was no complication following the embolisation. The amount of perioperative blood loss was only $700 \mathrm{ml}$ which is in line with the angiographic findings, likely indicating hypovascular metastasis. In a case with clear cut significant tumoral blush and easily-cannulated feeding artery, gel foam would not be our first line embolic agent.

As mentioned in the result, there was one case that we decided for on-table balloon-assisted C2 vertebrectomy. This patient was diagnosed with $\mathrm{C} 2$ vertebra chordoma. Balloon tamponade was used as temporary embolisation during the surgery to help reduce intraoperative blood loss. Documented blood loss was $1600 \mathrm{ml}$. According to experience publish in All India Institute of Medical Sciences by Sreejet Nair et al in 2013, chordoma has relatively low tumour vascularity ${ }^{21}$. Thus, balloon-assisted technique was sufficient for temporary tumour devascularisation of the tumour by placing balloon within the right vertebral artery. Permanent embolisation is not suitable as compromising vertebral artery was not an option. There were 10 patients who had complete embolisation. From this 10 patients, 3 patients were embolised using combined embolic agent, 4 patient were embolised using PVA only, 2 were embolised using coils and 1 patient was embolised using Gelfoam.

The remaining 4 patients had incomplete embolisation. The main reason for incomplete embolisation was difficult selective cannulation into the feeding artery. Some of the patients had multiple anastomosis with vital structure such as spinal cord and intercostal muscles that resulted in very risky embolisation, hence left non-embolised. From those who had incomplete embolisation, 2 patients were embolised using combined embolic agents, 1 patient embolised using coils and the remaining 1 patient embolised using Gelfoam. Those from completely embolised group were mainly using PVA particles as embolic agent.

We can deduce that embolic materials do not really determine the degree of embolisation. Study done by Barkefeld showed that there was no significant advantage of one embolic agent over another ${ }^{16}$. In fact, the material of choice were depending on the degree of tumour vascularization. Hence, the appearance of feeding arteries in angiogram were the important determinant of embolisation outcome. One way ANOVA test showed that there was significant difference in intraoperative blood loss between those who had complete embolisation and incomplete embolisation. This is similar as reported by Nair et al in his study, where complete embolisation is more effective in decreasing intra-operative blood loss compared to nearcomplete or partial embolisation ${ }^{21}$.

For obvious reason, type of operation plays important role in intraoperative blood loss. Complete removal of vertebral body (vertebrectomy) has shown to achieve superior decompression and long term results in comparison to posterior laminectomy. It is, however, associated with massive intraoperative blood loss, especially when dealing with hypervascular metastasis. Nine out of 15 patients in our study underwent vertebrectomy, and mean blood loss for those underwent this procedure was $1511 \mathrm{ml}$. Detail discussion on the technical aspect of the operation is not within scope of this study, nonetheless, we analysed the relation between duration of surgery and amount of blood loss. Pearson correlation test showed Pearson value of 0.78 indicating strong positive correlation; the longer the duration of surgery, usually indicate more complex operation resulting in more blood loss.

\section{CONCLUSION}

From our study, we conclude that pre-operative embolisation has significant role in reducing intra-operative blood loss especially in hypervascular spinal tumour and spinal metastasis. Our result is comparable with literature review done in other centres. Further study with larger sample size will give better evaluation of pre-operative embolisation impact on spinal surgery. It will also give better opportunity to assess multifactorial aspects that can affect the efficacy of embolisation.

\section{ACKNOWLEDGEMENTS}

I would like to thank you to my teachers, family and patients, those who helped to accomplished my study 


\section{APPENDIX 1}
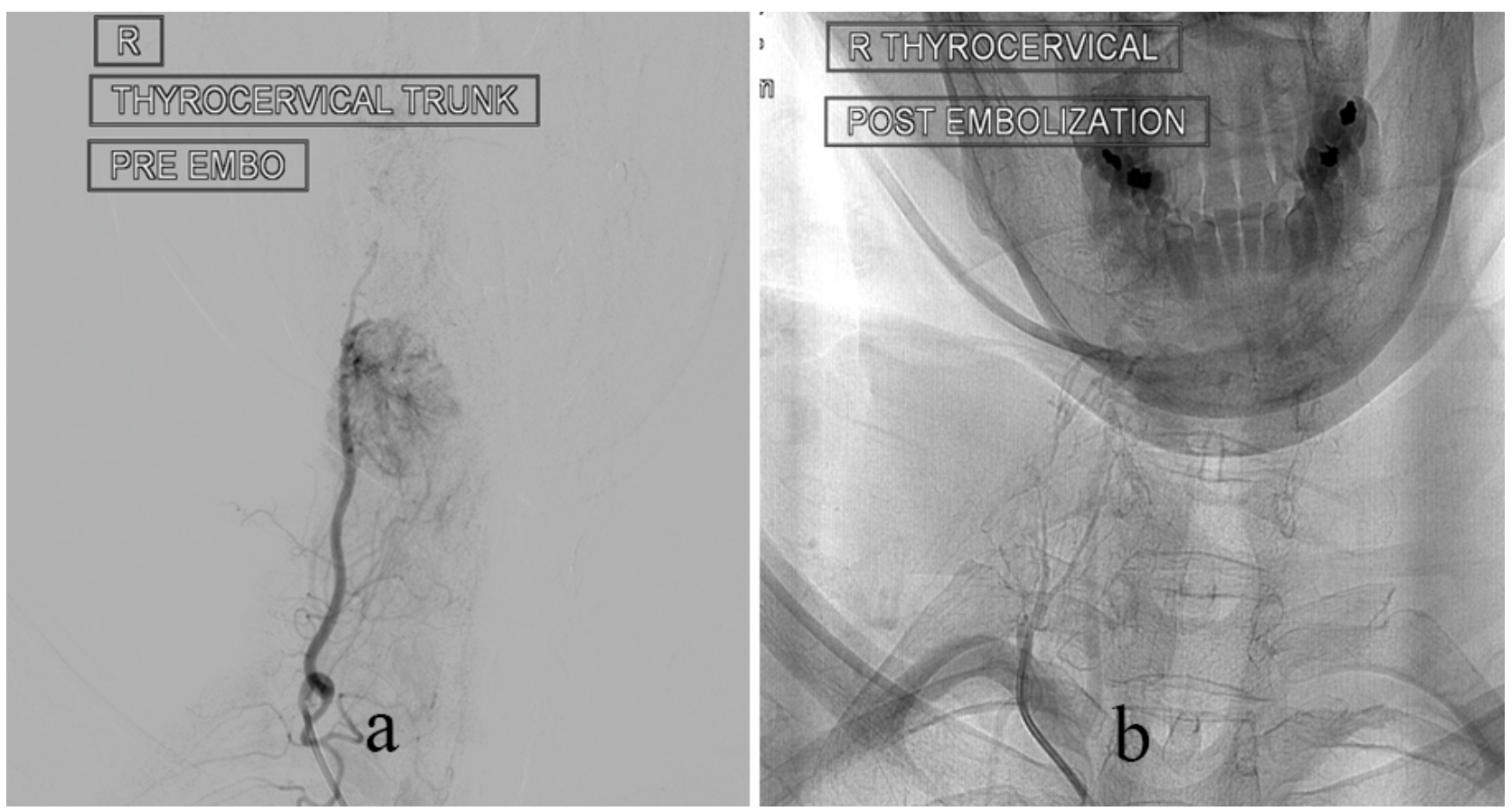

\section{Figure 3}

53-years-old, Malay lady with left orbital hemangiopericytoma with C5 spinal metastasis since 2008. Presented with 2 months history of right upper limb radiculopathy with weakness. Figure 3(a) There is tumoral blushed at the $\mathrm{C} 5 / \mathrm{C} 6$ region, from the right thyrocervical trunk whom was embolized using gelfoam with tip of catheter distal to the feeder. Figure 3(b) Post embolisation of the right thyrocervical trunk shows resolved tumoral blush from this feeder artery. The tumour also has other 3 feeder arteries, which also embolised except the one from left vertebral artery. Blood loss was recorded at $2200 \mathrm{ml}$.
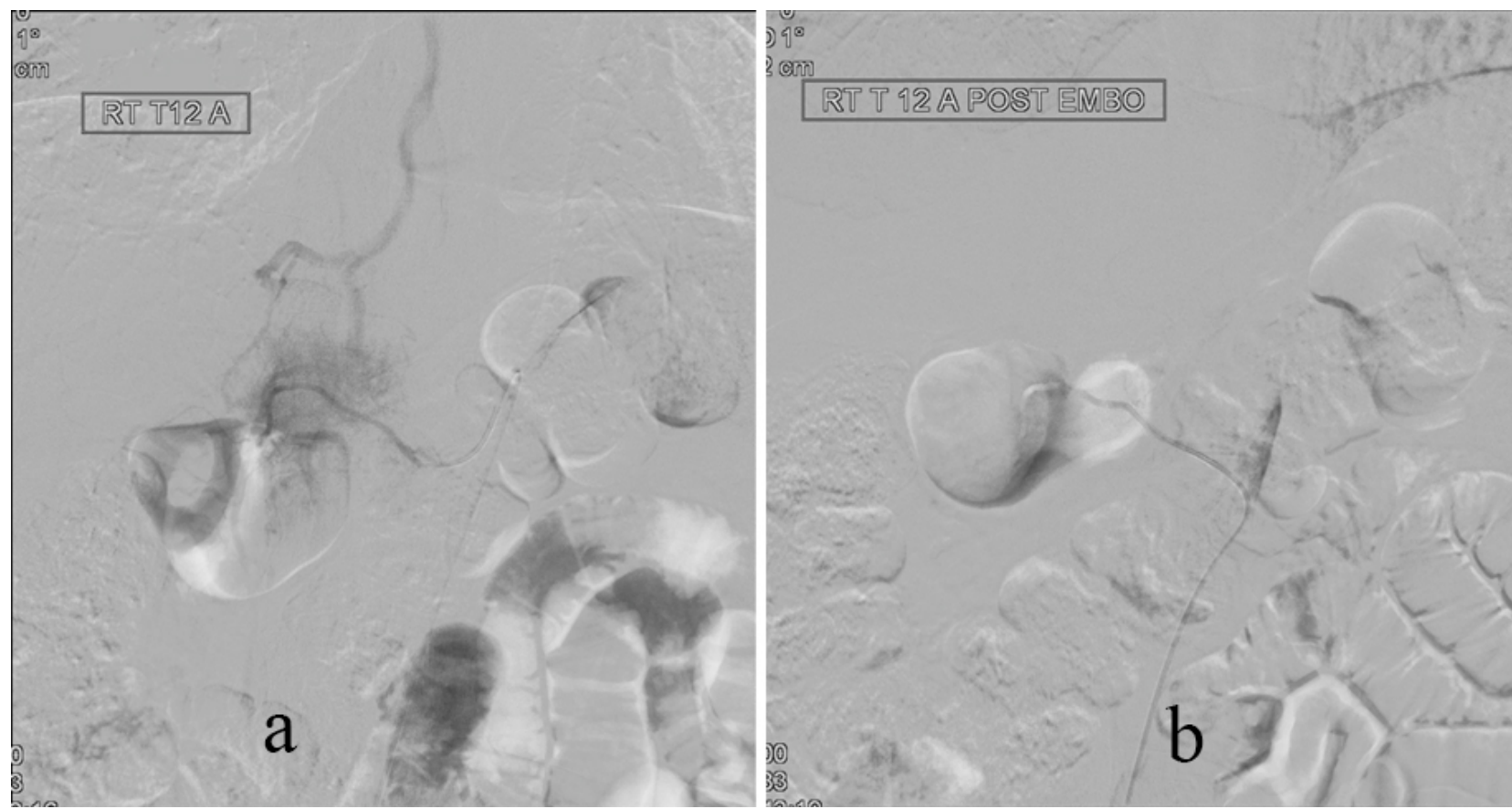

Figure 4

66-years-old, Chinese gentleman underlying prostate cancer with cervical, thoracic and lumbar metastasis. Figure 4(a) Tumoral blush seen from the right T12 spinal arteries. Figure 4(b) Post embolisation using gelfoam shows complete resolution of tumoral blushed post gelfoam injection. 


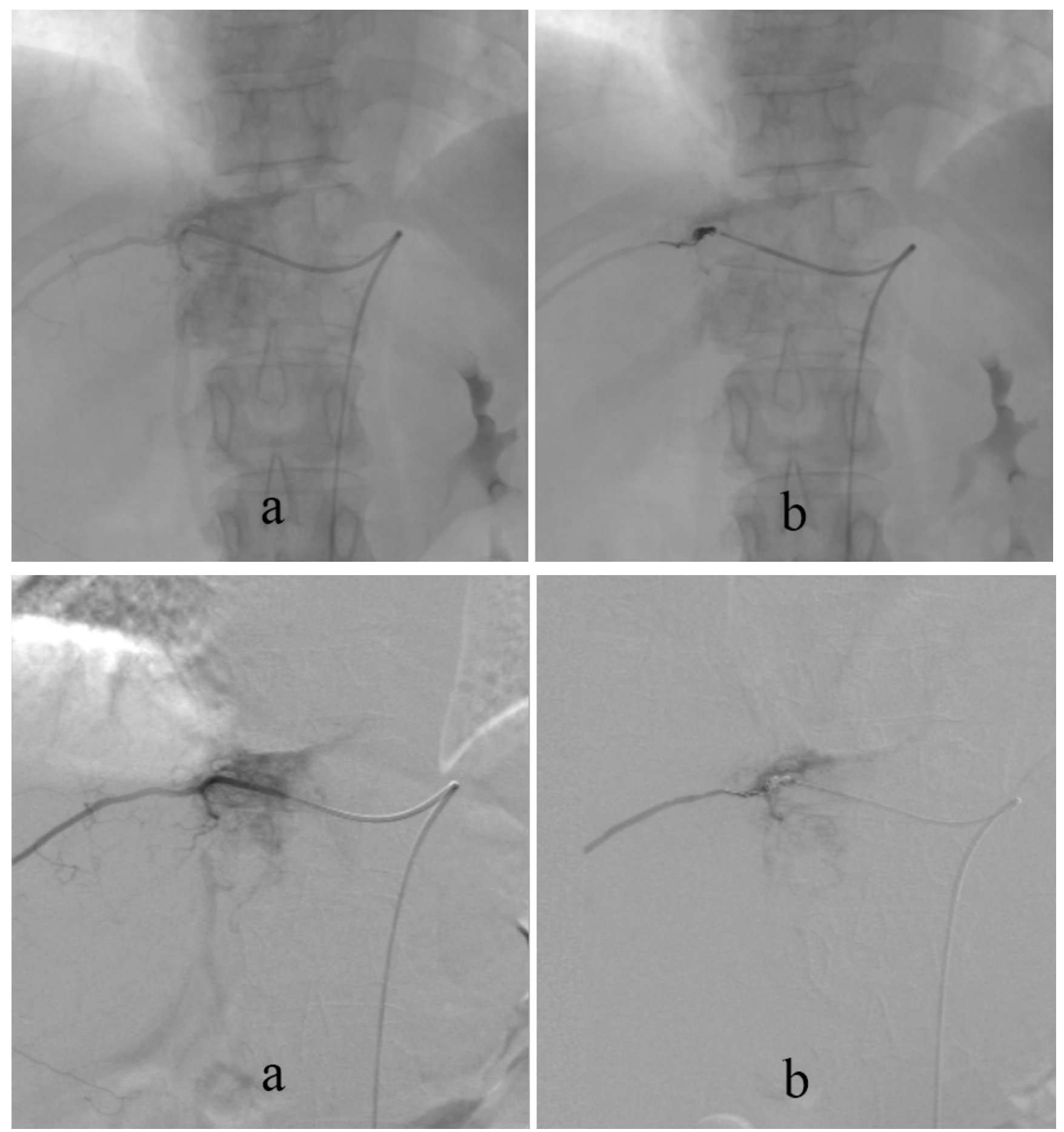

Figure 5

47-year-old, man gentleman, with primary lung bronchogenic carcinoma, with T9, T11 and T12 spinal metastasis. Figure 5(a) Tumoral blushed at the right T11/T12 region. Figure 5(b) Post embolisation with coil showed reduction of tumoral blushed. This patient had incomplete embolisation. Blood loss intraoperative documented at $700 \mathrm{ml}$. 


\section{REFERENCES}

1. B. Shaw, F. L. Mansfield, and L. Borges, "One-stage posterolateral decompression and stabilization for primary and metastatic vertebral tumors in the thoracic and lumbar spine," Journal of Neurosurgery, vol. 70, no. 3, pp. 405-410, 1989

2. N. Hosono, K. Yonenobu, T. Fuji, S. Ebara, K. Yamashita, išpiand K. Ono, "Orthopaedic management of spinal metastases," Clinical Orthopaedics and Related Research, no. 312, pp. 148- 159, 1995.

3. M. D. Abeloff, J. O. Armitage, J. E. Niederhuber, M. B. Kastan, and W. G. McKenna, Abeloff's Clinical Oncology, Churchill Livngstone Elsevier, Philadelphia, Pa, USA, 4th edition, 2008

4. W.F. Jaffe, Tumors and Timorous Conditions of the Bones and Joints, Lea and Febiger, Philadelphia, Pa, USA, 1958

5. O. V. Batson, "The role of the vertebral veins in metastatic processes," Annals of Internal Medicine, vol. 16, pp. 38-45, 1942

6. C. S. B. Galasko, "Mechanisms of bone destruction in the development of skeletal metastases," Nature, vol. 263, no. 5577, pp. 507-508, 1976

7. D. Togawa and K. U. Lewandrowsky, "The pathophysiology of spinal metastases," in Cancer in the Spine, R. F. McLain, Ed., Current Clinical Oncology, pp. 17-23, 2006

8. P. Black, "Spinal metastasis: current status and recommended guidelines for management," Neurosurgery, vol. 5, no. 6, pp. 726-746, 1979

9. Bartels RH, Van Der Linden YM Van Der Graft WT. Spinal extradural metastasis: review of current treatment options. CA Cancer J Clin 2008

10. Quan GM, Vital JM, Pointillart V. J Neurosurg Spine 2011 Outcomes of palliative surgery in metastatic disease of the cervical and cervicothoracic spine.

11. Palliative spinal reconstruction using cervical pedicle screws for metastatic lesions of the spine: a retrospective analysis of 32 cases. Spine 2006

12. A novel classification system for spinal instability in neoplastic disease: an evidence-based approach and expert consensus from the Spine Oncology Study Group. Fisher CG, Dipaola CP, Ryken TC et al. Spine 2010

13. Hall AJ, Machay NN. The results of laminec- tomy for compression of the cord or cauda equina by extradural malignant tumor. J Bone Joint Surg Br. 1973; 55(3):497-505

14. Sorensen PS, Borgensen SE, Rohde K, et al. Metastatic epidural spinal cord compression. Cancer. 1990; 65(7):1502-1508

15. Hess T, Kramann B, Schmidt E, Rupp S. Use of preoperative embolization in spinal meta- static resection. Arch Orthop Trauma Surg. 1997; 116(5):279282

16. Berkefeld J, Scale D, Kirchner J, Heinrich T, Kollath J. Hypervascular spinal tumors: infuence of the embolization technique on preoperative hemorrhage. AJNR. 1999; 20(5):757-763
17. Al wala awad, Kaith K Almefty, Andrew F Ducruet et al The efficacy and risk of preoperative embolization of spinal tumor. 2015

18. Clausen C, Dahl B, Frevert SC et al 2015. Preoperative embolization in surgical treatment of spinal metastases: single-blind, randomized controlled clinical trial of efficacy in decreasing intraoperative blood loss

19. Christoph JG, Mohamed S, Philip H et 2016. Preoperative embolization of spinal tumours: A systematic review and meta-analysis

20. Roshan Jha, Raju S, Shah Alam K et al 2016. Preoperative embolisation of primary bone tumors: A casecontrolled study

21. Sreejit Nair, YP Gobin, Lewis ZL et al 2013. Preoperative embolisation of hypervascular thoracic, lumbar and sacral spinal column tumor: Technique and outcome from single center

22. Harrigan M, Devikis J et al 2009. Arteriovenous malformation. Handbook of cerebrovascular disease and neurointerventional technique

23. Hu YC, Newman CB, Dashti SR et al 2011. Cranial dural arteriovenous fistula: Transarterial Onyx embolisation experience and technical nuances

24. Jiang C, Lc X, Li Y et al 2011. Transarterial Onyx packing of the transverse-sigmoid sinus for dural arteriovenous fistulas

25. Santillan A, Zink W, Lavi E et al 2011. Endovascular embolisation of cervical hemangiopericytoma with Onyx-18. Case report and literature review.

26. Thiex R, Harris MB, Sides C, Bono CM, Frerichs KU. The role of preoperative transarterial embolization in spinal tumours. A large single-centre experience. Spine J 2013; 13: 141-149 [PMID: 23218826 DOI: 10.1016/j.spinee.2012.10.031]

27. Ibrahim WH, Safran ZA, Hasan H, Zeid WA. Preoperative and therapeutic embolization of extremities of bone and soft tissue tumours. Angiology 2013; 64: 151-156 [PMID: 22323836 DOI: $10.1177 / 0003319711436075]$

28. Kobayashi K, Ozkan E, Tam A, Ensor J, Wallace MJ, Gupta S. Preoperative embolization of spinal tumors: variables affecting intraoperative blood loss after embolization. Acta Radiol 2012; 53: 935-942 [PMID: 22927661 DOI: 10.1258/ar.2012.120314]

29. Al-Hadithy N, Gikas P, Perera J, Aston W, Pollock R, Skinner J, Lotzof K, Cannon S, Briggs T. Pre-operative Embolization of Primary and Secondary Bone Tumours is safe and Effective: a Retrospective Study. World J Oncol 2011; 2: 319-322 [DOI: 10.4021/wjon389w]

30. Zhang HJ, Yang JJ, Lu JP, Lai CJ, Sheng J, Li YX, Hao Q, Zhang SM, Gupta S. Use of intra-arterial chemotherapy and embolization before limb salvage surgery for osteosarcoma of the lower extremity. Cardiovasc Intervent Radiol 2009; 32: 672-678 [PMID: 19296158 DOI: 10.1007/s00270-009-9546-2]

31. Lee VN, Nithyananth M, Cherian VM, Amritanand R, Venkatesh K, Sundararaj GD, Raghuram LN. Preoperative embolisation in benign bone tumour excision. J Orthop Surg (Hong Kong) 2008; 16: 80-83 [PMID: 18453665] 